\title{
Post-acute assessment programme for patients with traumatic brain injury: Measuring the gap between patients' expectations on entering and end of programme recommendations
}

\author{
U. Pouliquen ${ }^{1}$, F. Etcharry-Bouyx ${ }^{2}$, K. Pinon ${ }^{1,3}$, F. Patureau ${ }^{3}$, A. Petit ${ }^{1}$, A. Lambert ${ }^{3}$, \& I. Richard ${ }^{1}$ \\ ${ }^{1}$ LUNAM Université, Angers, France, Université Angers France, Angers, France and ${ }^{2}$ Department of Neurology, LUNAM Université, Angers, France, \\ ${ }^{3}$ UEROS Arceau Anjou, Angers, France
}

\section{Abstract}

Objective: To compare the expectations of patients with brain injury (TBI) entering a post-acute programme to the recommendations made at the end.

Design: Retrospective study (1997 and 2009).

Intervention: This 12-week post-acute programme included ecological multidisciplinary assessment of physical and cognitive disabilities, independence in activities of daily living and work abilities. Recommendations made at the conclusion of the programme included advice regarding the ability to work in an unsheltered or a sheltered environment and possible social activities.

Results: Two hundred and forty patients participated. The main objective of $95.8 \%$ was returnto-work: $93.7 \%$ expected a normal work environment, $2.1 \%$ considered a sheltered environment and $4 \%$ entered the programme with the aim of improving social abilities and integration in the community. The recommendations included return-to-work in $68.3 \%$ of cases, in an unsheltered environment in $44.2 \%$ and in a sheltered environment in $24.1 \%$ and advice for contact with social services in order to achieve better social integration in $31.7 \%$. There was a discrepancy between expectations and recommendations in half of the cases.

Conclusion: The discrepancy between patients' expectations and recommendations is in part due to the cognitive disorders; long-term rehabilitation programmes should focus on this issue.
\end{abstract}

\section{Keywords}

Return to work, traumatic brain injury, vocational rehabilitation

\section{History}

Received 1 April 2012

Revised 16 March 2013

Accepted 6 April 2013

Published online 18 June 2013

\section{Introduction}

The annual incidence of traumatic brain injury (TBI) in France is comprised of between 2-10/100 000 and appears to have remained relatively stable since the survey in Aquitaine in 1986 [1]. The recent epidemiological study performed in 2005 in Paris [2] confirmed a rate of 2.6/100 000 severe brain injuries. Findings from different studies are difficult to compare because of the variability of the inclusion criteria [3].

One of the main difficulties after brain injury is that of social and vocational integration. Life expectancy is near normal, but the neuropsychological and behavioural sequelae result in restriction of social participation [4]. Alaoui and Mazaux [5] confirmed the frequency of these disabilities in the long-term and reported an incidence of $52 \%$ for depressive mood, $46 \%$ for mental fatigue, $46 \%$ for memory impairment and $33 \%$ for reduction in initiative and motivation. These sequelae lead to restriction in social participation and are potentially major determinants of quality-of-life, defined as a sense of "well-being, moral and social capacity

Correspondence: Professor Isabelle Richard, University of Angers, LEEST EA INVS 4336, Rue haute de reculée, ANGERS Cedex 02, 49000 France. Tel: 336277385 47. Fax: 02413515 58; E-mail: isabelle.richard@univ-angers.fr to achieve goals'. Mailhan et al. [6] showed that satisfaction with quality-of-life was not linearly correlated with the degree of disability. One survey [7] studied life satisfaction, rated both by the patient and a relative, 7-10 years after the trauma in a population of 79 severe TBI. Thirty-one per cent of the patients still lived in the parental home and nearly $44 \%$ of the relatives described the impact of the injury as significant or unbearable. From the perspective of the patients, measured by the Fugl-Meyer life satisfaction questionnaire [8], employment status was the most important determinant of quality-oflife in 36\%, family relationships in $22 \%$ and independence in activities of daily life (ADLs) in 19\%. Only 28\% regarded their 'vocational situation' as satisfactory or very satisfactory.

The use of QOLIBRI [9], a disease-specific measure of health-related quality-of-life, has also shown that patients who work have a significantly higher total score than those who do not work (mean $=70.66$ vs. 56.05 , respectively).

These findings have led many countries to develop services. downstream from the phase of physical and cognitive rehabilitation focusing on improving return-to-work. The systematic review of Fadyl and McPherson [10] in 2009 identified three broad models: programme-based vocational rehabilitation inspired by the New York University Medical Centre Head Trauma Programme model [11], a Supported 
Employment model and a case co-ordination model. Programme-based vocational rehabilitation combines in varying proportions individualized intensive work skills rehabilitation and interventions within a structured programmed environment, guided work placement trials and job transition support. The Supported Employment model involves job placement, on-the-job training, and long-term support with job skills reinforcement through on-the-job coaching. This literature review concluded that there is a low level of evidence available for any of these models.

Such programmes have been developed in France over the last 20 years in a national framework [12] with the objectives of assessing the potential and difficulties of the trainee, assisting in defining a tailored lifeplan, training in vocational skills and proposing further orientation alternatives.

The evaluation of these services is difficult and often limited to quantitative indicators such as the population served or the rate of return-to-work. Some studies have described reduction of disability during the programme. However, the qualitative aspects of this service are more difficult to assess. In particular, there is little information concerning the issue of patients' and relatives' satisfaction and the determinants of their satisfaction. One of the challenges after a brain injury is to build a programme that can take into account both the actual difficulties of the participant and the patients' and relatives' expectations that are often determined by a desire to return to the pre-injury status. Such programmes may induce misunderstanding between the patient and his family in their search for an 'as before' and the health-professionals and social workers who are advising solutions such as sheltered work environments which may appear demeaning or discriminatory. The aim of this study was to evaluate to what extent the recommendations made at the end of a post-acute rehabilitation programme coincided or differed from the expectations of participants expressed when entering the programme.

\section{Subjects and methods}

\section{Participants}

All participants admitted to the programme between 1 January 1997 and 31 December 2009 were included in the study.

\section{Design}

A retrospective analysis was performed from standardized records in 2010 .

\section{Methods}

The criteria of admission to the programme were: aged above 16 years; a history of acquired brain injury; a stable medical state; the return of the patient to his everyday environment; and the request of the patient and/or relative.

The programme took place over 12 consecutive weeks, with the continuous intervention of a multidisciplinary team, and was divided into three stages. The team included a manager, a department head, a neuropsychologist, a psychologist, an occupational therapist, a neurologist and social workers. For each patient one of the team members was referent in order to facilitate exchanges and allow rapid adjustments.
During the first phase ( 3 weeks) each patient underwent assessment sessions conducted by the multidisciplinary team. The medical and personal history since the injury was documented. The physical, cognitive and behavioural disabilities were assessed as well as the perceptions of the patient regarding his/her situation and his/her expectations for the future. Assessment was mainly based on ecological tasks. The second phase ( 5 or 6 weeks) consisted of the development of a programme depending on the conclusions reached during the assessment phase and the implementation of specific retraining sessions. Neuropsychological rehabilitation was available. Temporary job placements in companies were possible during this period and training for autonomy in complex activities (transport, shopping) was provided in a real life environment. The third stage ( 3 or 4 weeks) was a phase of evaluation of the progress, validation of the programme and definition of the action plan. The professionals defined recommendations concerning the support requirements for social autonomy, possible activities and employability.

\section{Measurements}

Socioeconomic data were recorded: gender, pre-injury educational level, aetiopathology of the brain damage, age at the time of the accident and when entering the programme, interval between the injury and the programme, activity and family situation at the time of injury and on entering the programme.

The expectations expressed by the patient at entry were recorded, as well as the recommendations made at the end of the programme. This information was used to allocate the patient to one of the following groups:

- work activity in unsheltered environment, access to nonspecific educational programmes (for instance resuming studies);

- work activity in a sheltered work environment; and

- social integration, including access to social activities, to residential programmes and leisure activities in a specialized or community environment.

A binary variable was then used to define whether the expectations and recommendations were congruent (i.e. fell in the same category) or discrepant.

\section{Results}

Two hundred and forty patients participated in the programme between January 1997 and December 2009. Socioeconomic data at the time of the brain injury and at entrance are presented in Table I. The typical profile was that of a young man having sustained a traumatic brain injury and employed at the time of the accident.

At the beginning of the programme, $95.8 \%$ of the patients (230) expressed their wish to work. Only five (2.1\%) considered a sheltered environment. One hundred and fortynine $(66.2 \%)$ wished to work in a normal environment, 21 (9.3\%) were considering vocational training and $51(22.7 \%)$ wanted to re-define their career plan. Only $4.2 \%$ (10) of them gave priority to other means of social integration.

At the end of the programme, the recommendations were as follows: $68.3 \%$ (164) patients were encouraged to return to work, $44.2 \%$ (106) in an unsheltered environment and $24.1 \%$ 
Table I. Characteristics of the patients at the time of injury and at when entering the programme.

\begin{tabular}{|c|c|}
\hline & Participants $(\%)$ \\
\hline \multicolumn{2}{|l|}{ Gender } \\
\hline Male & $193(80.4 \%)$ \\
\hline Female & $47(19.6 \%)$ \\
\hline \multicolumn{2}{|l|}{ Age at onset of TBI } \\
\hline$<20$ years & $86(35.8 \%)$ \\
\hline $20-24$ & $44(18.3 \%)$ \\
\hline $25-29$ & $36(15 \%)$ \\
\hline $30-34$ & $27(11.3 \%)$ \\
\hline$>35$ & $47(19.6 \%)$ \\
\hline \multicolumn{2}{|c|}{ Aetiology of the brain injury } \\
\hline Traumatic Brain injury & $170(70.8 \%)$ \\
\hline Stroke & $28(11.7 \%)$ \\
\hline Tumour & $9(3.7 \%)$ \\
\hline Other & $33(13.8 \%)$ \\
\hline \multicolumn{2}{|c|}{ Partner status at the time of injury } \\
\hline Single, post-partnered & $166(69.2 \%)$ \\
\hline Partnered & $74(30.8 \%)$ \\
\hline \multicolumn{2}{|c|}{ Partner status when entering the programme } \\
\hline Single, post-partnered & $185(77 \%)$ \\
\hline Partnered & $55(23 \%)$ \\
\hline \multicolumn{2}{|c|}{ Employment situation prior to TBI } \\
\hline Employed or student & $200(83.3 \%)$ \\
\hline Unemployed & $40(16.7 \%)$ \\
\hline \multicolumn{2}{|c|}{ Employment situation when entering the programme } \\
\hline Employed or student & $15(6.2 \%)$ \\
\hline Unemployed & $225(93.8 \%)$ \\
\hline \multicolumn{2}{|c|}{ Time between injury and entry to the programme } \\
\hline$<2$ years & $14(5.8 \%)$ \\
\hline $2-6$ years & $147(61.3 \%)$ \\
\hline $6-10$ years & $28(11.7 \%)$ \\
\hline$>10$ years & $51(21.2 \%)$ \\
\hline
\end{tabular}

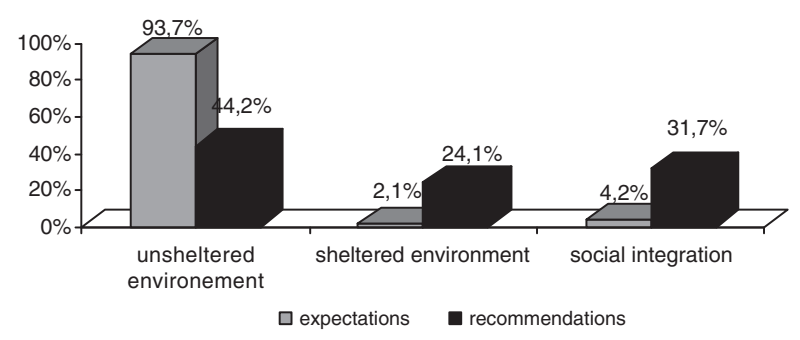

Figure 1. Comparison of the patient's expectations at entrance and of the end-of-programme recommendations.

(58) in a sheltered environment. Return to the previous job was recommended for nine patients. For $31.7 \%$ (76) patients, the conclusions of the assessment were to recommend social integration as a priority. Figure 1 illustrates these distributions.

The recommendations were congruent with the expectations of 116 patients (48.3\%) and different for 124 (51.7\%).

\section{Discussion}

The aim of this study was to evaluate the correspondence or difference between the expectations of TBI patients entering a post-acute assessment and rehabilitation programme and the recommendations made by the multidisciplinary team at the end of the programme.

In more than half of the cases, there was no correspondence between the expectations at the beginning and the final recommendations. The most common situation was that of a patient entering the programme with the aim of returning to work in an unsheltered environment and being advised after assessment to consider a sheltered environment or a programme focusing on other means of social integration.

The population in this study was very similar to those presented in many other studies [13-16]: $80 \%$ of the patients were male, young ( $60 \%$ under 30 years), in work or training at the time of injury (83.3\%), but not in employment when entering the programme (93.8\%). Nearly $71 \%$ had sustained severe brain trauma. The sample was probably fairly representative of the population served by such programmes [17].

Two major limitations of this study should be discussed:

- Patients' expectations were not recorded at the end of the programme. It was therefore not possible to determine whether the programme had enabled the patient to evaluate his difficulties and reconsider priorities. The discrepancy between the patients views and the recommendations were, thus, probably over-estimated. Nevertheless, the findings still reflected a gap that the patient needs to bridge in order to adapt his expectations.

- The long-term outcome and the implementation of the recommendations were not studied. Long-term outcome data are available for similar programmes in the study by Le Gall et al. [18]. At the end of this programme, $36 \%$ of patients were deemed able to return-to-work or enter vocational training programmes, $13 \%$ were referred to voluntary, leisure activities and $51 \%$ were not considered to be employable. Five years later, $42.6 \%$ were indeed working, 9.3\% were enrolled in training programmes and $46 \%$ were involved in leisure activities. Despite this slight increase in patients eventually back at work, $44 \%$ of the patients and 52\% of their relatives remained dissatisfied about their quality-of-life.

One of the key features of this programme was that it was based not only on standardized paper tests assessing executive functions [19], memory [20] and intellectual efficiency, but mainly on a comprehensive ecological assessment. The need for ecological assessment was emphasized by the reports by Shallice and Burgess [21] and Lesak [22] in the 1990s which showed a discrepancy between normal range performance on conventional tests and evidence of disability when ecological tests were used. Such results were also found in the study by Le Thiec and Jokic [23] comparing the performance of severe TBI assessed by conventional neuropsychological tests or Multiple Errands Test. During this programme the patient was faced with the real-life work environment, its constraints and contingencies. This allows better assessment of possible participation. These results confirmed that these scenarios unmask difficulties that remained under-estimated, at least by the patient.

The difference between patients' expectations and recommendations was high in this study. This probably entails a risk of psychological distress for the patient and may jeopardize the implementation of the recommended measures. The difference most probably had several causes. Anosognosia has frequently been described, in particular by Prigatano and Altman [24], and this study can be interpreted as a confirmation of the persistence of this condition in the very long-term. These authors showed that TBI patients do not 
adequately perceive the significant changes in their cognitive and behavioural functioning. Oppenheim-Gluckman et al. [25] compared information from interviews with patients and their families and the results of the Patient Competency Rating Scale (PCRS) and the Neurobehavioural Rating ScaleRevised (NRS-R) [26]. Their study showed that patients who under-estimated their disabilities tended to be those who presented the most severe memory and behavioural loss. This result could also be partly due to inadequate previous assessments, centred on conventional neuropsychological tests, which do not reveal the reality of post- injury loss.

This study showed that the differences should in all cases be addressed specifically and this has led to modifications in the programme. One of the main issues is to reduce as much as possible the gap between patient's expectations and what the reality of the cognitive and behavioural disabilities allows, but in most cases the gap appears to be such that it is doubtful that it can be overcome in a 12-week programme. Assessment could be divided and extended over a longer period of time in order to allow the patient to accept the conclusions, adjust his plans and discuss further the possibilities. Psychological support should be available during and after the programme in order to help and develop coping strategies. Further studies are required and should include qualitative single case studies in order to improve understanding of how this gap might be handled by patients, both during and after the programme.

\section{Conclusion}

Most TBI patients entering this post-acute assessment and rehabilitation programme expressed the wish to return-towork. Ecological multidisciplinary assessment revealed the persistence of disabilities which were judged to be incompatible with employability in an unsheltered environment and the end-of-programme recommendations differed significantly from the patients expectations in more than half of the cases. These results revealed both the persistence of anosognosia in the very long-term and the need for ecological assessment. It also emphasized the need to adapt long-term follow-up in order to address specifically the question of the difference between patients expectations and realistic options.

\section{Declaration of interest}

The authors report no conflicts of interest. The authors alone are responsible for the content and writing of the paper.

\section{References}

1. Tiret L, Hausherr E, Thicoïpé M, Garros B, Maurette P, Castel JP, Hatton F. The epidemiology of head trauma in Aquitaine (France) 1986: A community-based study of hospital admissions and deaths. International Journal of Epidemiology 1990;19:133-140.

2. Aegerter P, Boumendil A, Tazarourte K, Vigué B, Dolveck F, Weiss J-J, Azouvi P. Epidémiologie du traumatisme crânien grave en Ile-de-France. Rev Epid Santé Pub 2008;5S:264.

3. Mathé JF, Richard I, Rome J; Santé publique, traumatisés crâniens graves. Aspects épidémiologiques et financiers, structures et filières de soins. Annales de Réadaptation et de Médecine Physique 2005; 24:688-694.

4. Temkin N, Corrigan J, Dikmen S. Social functionning after traumatic brain injury. Journal of Head Trauma Rehabilitation 2009;24:460-467.
5. Alaoui P, Mazaux JM. Devenir neuropsychologique à long terme des traumatisés crâniens. Evaluation à 5 ans des troubles neuropsychologiques et comportementaux par l'échelle neurocomportementale révisée (à propos de 79 cas). Annales de Réadaptation et de Médecine Physique 1998;41:171-181.

6. Mailhan L, Azouvi P, Dazord A. Life satisfaction after severe traumatic brain injury. Brain Injury 2005;19:227-238.

7. Quintard B, Croze P, Mazaux JM, Joseph PA. Satisfaction de vie et devenir psychosocial des traumatisés crâniens graves en Aquitaine. Annales de Réadaptation et de Médecine Physique 2002;45: 456-465.

8. Fugl-Meyer A, Branholm I, Fugl-Meyer K. Happiness and domain specific life satisfaction in adult northern Swedes. Clinical Rehabilitation 1991;5:25-33.

9. Truelle J-L, Koskinen S, Hawthorne G. Quality of life after traumatic brain injury: The clinical use of the QOLIBRI, a novel disease-specific instrument. Brain Injury 2010;24:1272-1291.

10. Fadyl JK, McPherson K. Approaches to vocational rehabilitation after traumatic brain injury: A review of the evidence. Journal of Head Trauma Rehabilitation 2009;24:195-212.

11. Ben Yishay Y, Silver SM, Piasetsky E, Rattock J. Relationship between employability and vocational outcome after intensive holistic cognitive rehabilitation. Jornal of Head Trauma Rehabilitation 1987;2:35-48

12. Circulaire DHOS/SDO/01/DGS/SD5D/DGAS/PHAN/3 B $\mathrm{n}^{\circ}$ 2004-280 du 18 juin 2004 relative à la filière de prise en charge sanitaire, médico-sociale et sociale des traumatisés crânio-cérébraux et des traumatisés médullaires.

13. Teasdale T, Christensen A-L, Pinner E. Psychosocial rehabilitation of cranial trauma and stroke patients. Brain Injury 1993;7:535-542.

14. Van Velzen JM, Van Bennekom CAM, Edelaar MJA, Sluiter JK. How many people return to work after acquired brain injury? A systematic review. Brain Injury 2009;23:473-488.

15. William C, Walker MD, Jennifer H. Occupationnal categories and return to work after traumatic brain injury: A multicenter study. Archives of Physical Medicine \& Rehabilitation 2006;87: $1576-1582$.

16. Majdan M, Mauritz W, Brazinova A. Severity and outcome of traumatic brain injuries with different causes of injury. Brain Injury 2011;25:797-805.

17. Avesani R, Salvi L. Reintegration after severe brain injury: A retrospective study. Brain Injury 2005;19:933-939.

18. Le Gall C, Lamothe G, Mazaux JM. Programme d'aide à la réinsertion sociale et professionnelle de jeunes adultes cérébrolésés: Résultats à cinq ans du réseau UEROS- Aquitaine. Annales de Réadaptation et de Médecine Physique 2006;50:5-13.

19. Chevignard M, Taillefer C. An ecological assessment of the dysexecutive syndrome with a cooking task. Neuropsychological Rehabilitation 2008;18:461-485.

20. Asloun S, Soury S, Couillet J. Interactions between divided attention and working memory load in patients with severe traumatic brain injury. Journal of Clinical \& Experimental Neuropsychology 2007; in press.

21. Shallice T, Burgess PW. Deficits in strategy application following frontal lobe damage in man. Brain 1991;114:727-741.

22. Lezak MD. Newer contributions to the neuropsychological assessment of executive functions. Journal of Head Trauma Rehabilitation 1993;1:24-31.

23. Le Thiec F, Jokic C. Evaluation écologique des fonctions exécutives chez les traumatisés crâniens graves: Pour une meilleure approche du handicap. Annales de Réadaptation et de Médecine Physique 1999;42:1-18.

24. Prigatano GP, Altman IM. Impaired awareness of behavioural limitations after traumatic brain injury. Archives of Physical Medicine \& Rehabilitation 1990;71:1058-1064.

25. Oppenheim-Gluckman H, Fayol P, Dumond JJ, Azouvi P. The psychopathology of the unawareness of cognitive impairments and behavioural limitations in traumatic brain-injured patients. Annales de Réadaptation et de Médecine Physique 2003; $46: 41-48$.

26. Soury S, Mazaux JM. The neurobehavioral rating scalerevised (NSR-R): Assessment of concurrent validity. Annales de Réadaptation et de Médecine Physique 2005;48:61-70. 
Copyright of Brain Injury is the property of Taylor \& Francis Ltd and its content may not be copied or emailed to multiple sites or posted to a listserv without the copyright holder's express written permission. However, users may print, download, or email articles for individual use. 